\section{Cureus}

\title{
Living with Hemoglobin of 3.7 After Bariatric Surgery! Follow-up is Key to Preventing Adverse Outcomes
}

\author{
Dipti Sagar $^{1}$, T. S. Dharmarajan ${ }^{2}$ \\ 1. Medicine, Albert Einstein College of Medicine 2. Montefiore Medical Center, Albert Einstein College of \\ Medicine
}

$\square$ Corresponding author: Dipti Sagar, diptisagar241@gmail.com

Disclosures can be found in Additional Information at the end of the article

\section{Abstract}

Gastric bypass surgery may be a boon to some but long-term sequelae, although common, escape timely detection. Routine and long-term follow-up of patients post-bariatric surgery is key to early detection of several treatable problems. Presented is a case where the patient received inadequate follow-up after bariatric surgery and required hospitalization with severe fatigue and depression due to a hemoglobin level of $3.7 \mathrm{~g} / \mathrm{dl}$. While gastric bypass procedures help treat morbid obesity with high success rates and even cure diabetes, long-term micronutrient deficiencies can occur and cause severe life threatening manifestations. This case illustrates the importance of providing lifelong follow-up of nutrient status following bariatric surgery.

Categories: Internal Medicine, Gastroenterology, General Surgery

Keywords: bariatric surgery, nutritional deficiencies following bariatric surgery, anemia and bariatric surgery, adverse outcomes following bariatric surgery, obesity and bariatric surgery, depression and bariatric surgery

\section{Introduction}

Obesity is commonly encountered in the United States (US). Several reviews and guidelines emphasize the importance of screening for overweight and obesity disorders [1-7]. Recently, the Obesity Society, in collaboration with the American College of Cardiology/American Heart Association (ACC/AHA), has issued a guideline on the management of overweight and obesity disorders and provided suggestions to better address overweight or obese patients [1]. American adults consume far more calories than required, leading to several preventable health disorders, such as overweight and morbid obesity states, hypertension, diabetes, hyperlipidemia, osteoarthritis, gall bladder disease, sleep apnea, and even some cancers, many in conjunction with premature all cause and cardiovascular disease-related mortality [7]. The National Health and Nutrition Examination Survey (NHANES) data suggests that the average daily calorie consumption is 2,475 for men and 1,833 calories for women in the US. The report of the United States Dietary Guidelines Advisory Committee states that over the past few decades, daily calorie consumption has gradually increased by 200 to 600 calories per individual in this country.

The approaches to addressing obesity include a combination of lifestyle measures, largely by promoting a decline in caloric intake through use of specific diet prescriptions. In addition, targeted weight loss must be achieved by an increase in physical activity as part of programs on a group or individual basis. When diet and exercise fail to produce results, options include the 


\section{Cureus}

use of medications and surgery. Many medications approved for short-term and long-term use for weight loss have adverse effects, requiring a risk benefit analysis prior to prescribing [6].

When lifestyle measures and medications fail to produce required results, surgery becomes a consideration. According to the American Society for Bariatric Surgery (now the American Society for Metabolic and Bariatric Surgery (ASMBS)), the number of bariatric procedures increased from about 16,000 in the early 1990 s to over 103,000 in 2003 . The ASMBS estimates that 220,000 people in the United States had bariatric surgery in 2008. Bypass surgery has shown much promise and benefits, including the amelioration of diabetes, hyperlipidemia, and additional disorders besides weight loss; however, one must not fail to recognize the complications and undesired consequences following surgical management of obesity [8-18].

We illustrate the statement with a case wherein the patient developed a common complication that was life-threatening following bariatric surgery for morbid obesity and the course escaped attention until a very late stage. Primary care physicians must bear the responsibility to recognize and address at least the common adverse outcomes following bariatric surgery.

\section{Case Presentation}

A 49-year-old female with history of depression for years was hospitalized with extreme fatigue, palpitations, and lightheadedness for several weeks, and with recent worsening. She had undergone Roux-en-Y gastric bypass surgery 11 years earlier when she weighed 265 pounds (BMI 47). Post-surgery, her weight came down to 120 pounds (BMI 21.9) over eight to nine years. Her hemoglobin $(\mathrm{Hb})$ was $6.2 \mathrm{~g} / \mathrm{dl}$ in her primary physician's office six months prior to the current hospitalization. Although she held her job as a secretary, she was apparently no longer living with her husband following a strained relationship. She was also non-adherent to follow-up and medication intake.

The patient's hemoglobin and hematocrit at hospitalization were $3.7 \mathrm{~g} / \mathrm{dl}$ and 12.2 , respectively; the serum ferritin was virtually non-existent at $3 \mathrm{ng} / \mathrm{ml}$. Additional studies: serum iron - $14 \mathrm{mcg} / \mathrm{dl}$ (normal: 65-175); total iron binding capacity (TIBC) - $505 \mathrm{mcg} / \mathrm{dl}$ (normal 250410); transferrin - $404 \mathrm{mg} / \mathrm{dl}$ (N: 204-360); transferrin saturation - 3\% (normal: 26-42); reticulocyte count - 2\%; vitamin B12 level - $1551 \mathrm{pg} / \mathrm{ml}$ (on B12 supplements), serum folate 17.8 units; $25(\mathrm{OH})$ vitamin D - $15.3 \mathrm{ng} / \mathrm{ml}$; serum calcium - $8.7 \mathrm{mg} / \mathrm{dl}$; phosphorous - $2.4 \mathrm{mg} / \mathrm{dl}$; and prothrombin time normal at $12.8 \mathrm{sec}$. The values confirmed severe iron deficiency. During hospitalization, she received three units packed red cells; colonoscopy and gastroduodenoscopy, obtained after informed consent, did not indicate a cause for anemia (Figures 1, 2).
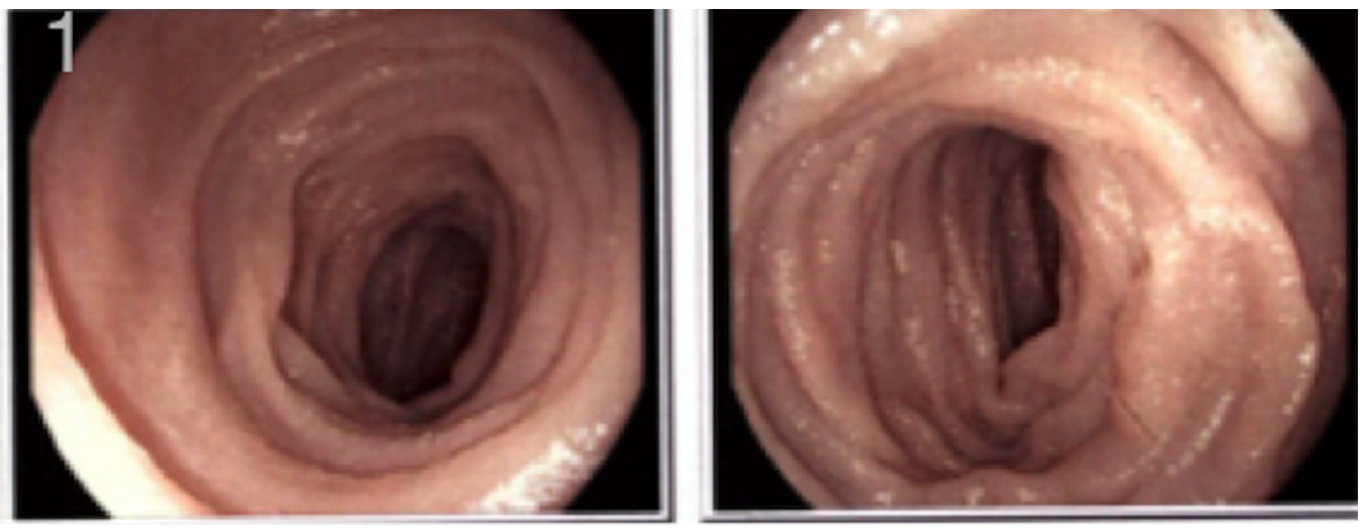

\section{FIGURE 1: Esophagogastroduodenoscopy}

Esophagogastroduodenoscopy: Normal-appearing anastomosis, normal gastro-esophageal 


\section{Cureus}

junction, normal esophagus,

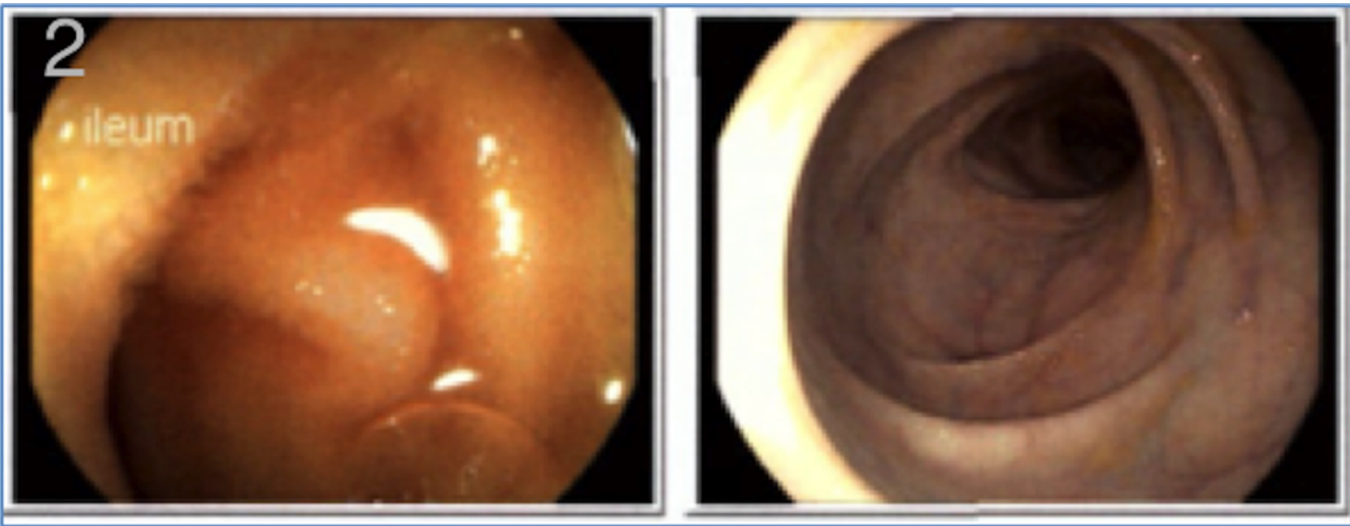

FIGURE 2: Colonoscopy

Colonoscopy: Normal colonic mucosa, normal terminal ileum.

The anemia was now deemed to be from iron deficiency, presumably from malabsorption of iron.

The patient's manifestations improved dramatically following transfusion, prompting discharge on weekly iron infusion and follow-up. Discharge $\mathrm{Hb}$ and hematocrit were $7.8 \mathrm{~g} / \mathrm{dl}$ and 25.6, respectively. She also received monthly vitamin B12 injections. Over months, the $\mathrm{Hb}$ normalized to 13.8 and the serum ferritin improved to $26 \mathrm{ng} / \mathrm{dl}$ with a transferrin saturation of 26 (normal).

\section{Discussion}

The prevalence of obesity in the United States exceeds 30\% in adults and is associated with high risk of death, whereas weight reduction lowers the incidence of morbidity and mortality. A BMI at or $>35 \mathrm{~kg} / \mathrm{m}^{2}$ is associated with a $200 \%$ increase in health care costs compared to normal weight ranges. When behavioral counseling interventions and pharmacologic measures fail, gastric bypass procedures are utilized to treat morbid obesity, often with high success rates [1012]. Long-term mortality, particularly from diabetes, heart disease, and cancer, is significantly reduced following gastric bypass surgery [9-12].

Although bariatric surgery provides unambiguous benefits to the majority of obese patients, there remain risks. Over the long term, significant micronutrient deficiencies are common. Occult nutritional deficiencies develop depending on dietary habits and additional predispositions [7-8]. By altering the anatomical structure and physiology of the digestive system, bariatric surgery predisposes to consumption of smaller portions of food, along with reduced surface area for nutrient absorption, altered gastrointestinal motility, and possible bacterial overgrowth (especially in diabetics), setting up the background for malabsorption [7-8, 14-17].

Anemia, the dominant problem in our patient, can develop following bariatric surgery and may be severe enough to cause adverse outcomes or affect quality of life. The main causes of 
nutritional anemia following bariatric surgery include deficiency of iron, folic acid, and vitamin B12, individually or in combination, with folate deficiency the least likely basis; additional factors unrelated to surgery can coexist and may be responsible, such as use of proton pump inhibitors or the presence of alcoholism [15, 17, 19-22].

Nearly half the patients with RYGB surgery develop iron deficiency [22]. The pathogenesis of iron deficiency is multifactorial and includes dietary components and alterations in physiology [21-22]. Normally, ingested dietary iron in ferric form is poorly absorbed until it is reduced to ferrous state in the stomach, facilitated by hydrochloric acid. Iron is absorbed in the duodenum and proximal jejunum; alteration in anatomy, along with post-surgery achlorhydria, can impair iron absorption. The common practice of prophylactic use of $\mathrm{H} 2$ blockers and proton pump inhibitors to reduce acid secretion can interfere with iron and B12 absorption [19-20, 23]. Consumption of iron rich food, such as red meat, may decline following surgery due to altered food preferences, worsening the predisposition to iron deficiency. When iron deficiency does occur, iron supplementation is necessary; iron is often recommended following gastric bypass $[22,24]$. Iron deficiency presents primarily as a microcytic anemia and is confirmed by a measure of hemoglobin, blood smear for microcytic, hypochromic red cells and determining serum iron, iron binding capacity, transferrin saturation, and ferritin assays periodically [2425]. Iron supplements must be administered and tailored to patient [25]; intravenous infusion of iron is indicated when intolerant to iron. Oral iron is best administered as ferrous sulfate, $325 \mathrm{mg}$ daily, on an empty stomach; larger doses are not necessarily more effective and in fact may be associated with more side-effects [26, 27].

Besides B12 and iron deficiency, nutritional anemias involving protein, copper, selenium, and zinc may result from malabsorption following bariatric surgery and require consideration when routine screening is negative for iron deficiency anemia [21, 25-26].

Vitamin B12 or cobalamin deficiency occurs in 26-70\% of gastric bypass patients [25-26, 28-31]. Absorption of cobalamin is a complex process involving a series of steps [28-31]. Pepsin and hydrochloric acid cleave B12 from food protein in the stomach as an initial step; free B12 binds to $\mathrm{R}$ factor from saliva and exits the stomach, where in the alkaline medium of the duodenum, B12 splits from R factor to bind to intrinsic factor outside the stomach. Achlorhydria or hypochlorhydria, gastritis of any cause, and decreased B12 dietary consumption (from low intake of meat, poultry, fish, and dairy) or inadequate secretion of intrinsic factor may contribute to B12 deficiency. Absence of part or much of the stomach is an important cause. Following bariatric surgery, cobalamin deficiency invariably occurs over time. Manifestations include macrocytosis, megaloblastic anemia, thrombocytopenia, and leukopenia, all detectable by laboratory tests, besides several neurological or neuropsychiatric manifestations, including depression. Neuropsychiatric manifestations occur with B12 deficiency and range from depression to psychoses and dementia, besides neurological deficits. The patient's behavioral manifestations may not have helped her marital relationship.

Early detection of B12 deficiency is important, as most manifestations from deficiency are reversible with B12 supplementation at early stages. The gastrointestinal epithelium also undergoes megaloblastic changes from B12 deficiency leading to secondary malabsorption and deficiency of B12 and other nutrients [28, 30-31]. B12 deficiency is easily correctable by replacement of the vitamin via the oral, intramuscular, intranasal, or sublingual routes.

While achlorhydria contributes predominantly to iron and B12 deficiency, folate absorption is also facilitated by hydrochloric acid, mainly in the proximal small bowel [30-31]. Folate deficiency is a serious threat for women who become pregnant after gastric bypass surgery as the deficiency may lead to neural tube defects in infants. Folic acid supplements are indicated for gastric bypass patients, especially for women of the reproductive age group. 
Thiamine cannot be synthesized by humans and is not stored in large amounts. Restrictive diets, along with redirection of nutrients in the proximal small bowel (the site of absorption of B vitamins), may result in thiamine deficiency and the Wernicke-Korsakoff syndrome. A daily multivitamin with thiamine and additional minerals, such as elemental zinc, will help prevent deficiency.

Dietary calcium is mainly absorbed in the duodenum. Obesity is associated with vitamin D deficiency due to decreased sun exposure, insufficient intake, and reduced bioavailability of vitamin D, which is sequestrated in fat [15-17, 32-33]. Further, after certain types of bariatric surgery, ingested vitamin D does not pass through the duodenum for absorption, resulting in calcium deficiency. Poor adherence or reduction in dietary calcium and vitamin D intake, reduced exposure to sunlight, and failure to follow-up may exacerbate vitamin D and calcium deficiencies [26, 32]. Negative calcium balance and vitamin D deficiency predispose to osteoporosis and osteomalacia following gastric bypass. Guidelines recommend monitoring for calcium, phosphorous, vitamin D, PTH, and alkaline phosphatase levels every six months, along with an annual bone densitometry, until adequate control is ensured [2, 32]. Patients should be maintained on 1000-1200 mg calcium and 600-800 units of vitamin D daily, after correction of deficiency.

Table 1 summarizes the cause of nutrient deficiencies following bariatric surgery and their management. 


\section{Cureus}

\begin{tabular}{|c|c|c|c|}
\hline Deficiency & Causes & Prevention & Treatment \\
\hline Iron & $\begin{array}{l}\text { 1. Achlorhydria 2. Inappropriate use of } \mathrm{H} 2 \\
\text { receptor blockers and PPIs } 3 \text {. Restrictive } \\
\text { diets } 4 \text {. Intolerance to red meat. }\end{array}$ & $\begin{array}{l}\text { Minimize use of } \\
\text { acid blocking } \\
\text { agents Minimize } \\
\text { use of restrictive } \\
\text { diets }\end{array}$ & Ferrous sulfate $325 \mathrm{mg} /$ day \\
\hline Vitamin B12 & $\begin{array}{l}\text { 1. Achlorhydria } 2 \text {. Use of PPIs } 3 \text {. Loss of } \\
\text { intrinsic factor } 4 \text {. Bacterial overgrowth in } \\
\text { the Gl tract } 5 \text {. Restrictive diets }\end{array}$ & $\begin{array}{l}\text { Administer } \\
\text { vitamin B12 }\end{array}$ & $\begin{array}{l}\text { Administer oral B12 at } 500- \\
1000 \text { mcg/d or } 100-1000 \mathrm{mcg} \\
\text { IM every } 1-3 \text { months }\end{array}$ \\
\hline Folic acid & 1. Achlorhydria & Folate rich foods & Folic acid $0.4-1.0 \mathrm{mg} / \mathrm{d}$ \\
\hline Vitamins $A, D, E, K$ & $\begin{array}{l}\text { 1. Bypassing the duodenum delays mixing } \\
\text { of dietary fat with pancreatic enzymes and } \\
\text { bile salts } 2 \text {. Vitamin } D \text { deficiency less likely, } \\
\text { absorbed in jejunum and ileum. }\end{array}$ & $\begin{array}{l}\text { Provide the } \\
\text { essential } \\
\text { vitamins. }\end{array}$ & $\begin{array}{l}\text { Correct deficiencies when } \\
\text { present. Provide recommended } \\
\text { daily maintenance amounts of } \\
\text { vitamins to prevent recurrence }\end{array}$ \\
\hline Calcium & $\begin{array}{l}\text { 1. Occurs with absence of acid, or } \\
\text { following vitamin D deficiency } 2 \text {. Lactose } \\
\text { intolerance }\end{array}$ & $\begin{array}{l}\text { Provide calcium } \\
\text { with vitamin D } \\
\text { primarily as diet } \\
\text { or supplements. }\end{array}$ & $\begin{array}{l}1000-1200 \mathrm{mg} / \mathrm{d} \text { elemental } \\
\text { calcium }\end{array}$ \\
\hline Thiamine & 1. Vomiting 2.Restrictive diet & $\begin{array}{l}\text { Daily } \\
\text { multivitamins }\end{array}$ & $\begin{array}{l}\text { Oral or intravenous thiamine } \\
\text { supplements }\end{array}$ \\
\hline Zinc, copper & 1. Restrictive diets & Appropriate diet & $\begin{array}{l}\text { Supplements when diet is } \\
\text { inadequate }\end{array}$ \\
\hline
\end{tabular}

TABLE 1: Nutrient deficiencies following gastric bypass: Basis and management[1417]

An obese person has a $55 \%$ increased risk of developing depression over time, whereas depressed people have a $58 \%$ increased risk of becoming obese [34]. A recent study noted suicide rates after bariatric surgery to be five times that of general population [35]. The need for post-surgery follow-up specifically for depression should be emphasized [25, 36]. Psychological triggers for depression include expectation for a better quality of life post-surgery, food restrictions, difficulty in accepting changes in body image, new eating habits, and eating disorders. Psychological evaluation is warranted pre-surgery to address untreated depression and fully evaluate the patient's understanding about the risk of psychological issues after surgery [36].

Addressing the psychosocial status of bariatric surgery patients will minimize the potential negative impact postoperatively $[3,36]$. Patients are ideally provided education before surgery regarding the possibility of depression in the postoperative period; a change in mood should prompt evaluation [3]. Treatment involves identifying triggers, individual therapy, support groups, and antidepressant medications [36].

Our patient had been depressed for years while she was obese; depression continued even after 


\section{Cureus}

surgery. She had seen a psychiatrist and was on three prescription medications for depression. Anemia may have contributed to her fatigue, while fatigue made her depression worse. Her symptoms markedly improved after anemia was corrected. Though separated from her husband, it is amazing that she functioned in her job for even a month prior to hospitalization and lived with a $\mathrm{Hb}$ below $4 \mathrm{~g} / \mathrm{dl}$.

Bariatric surgery patients require lifelong follow-up of body mass index, nutritional status for deficiencies, and psychological well-being. Other complications, such as dumping syndrome, may follow surgery, but are beyond the scope of discussion here. Excellent results can be obtained from patient adherence to recommended changes in lifestyle and activity, and the prompt detection and management of nutritional deficiencies by the health care providers [12, 25]. 


\section{Cureus}

\section{Visit Frequency}

Initial evaluation within weeks after surgery

Follow up with interval visits until stable

Once stable, one to two visits per year, with physician and surgeon

Additional visits recommended for new manifestations

\section{Monitor}

Weight changes (loss or gain)

For evidence of new manifestations

Adherence to dietary and physical activity recommendations

Assess mood, in particular screen for depression

Evaluate the need for support groups or referrals to other specialists

\section{Laboratory Tests}

Complete blood count

Routine chemistries (renal and hepatic function, electrolytes)

Nutrient status: vitamins B12, folic acid, D, ferritin, transferrin saturation

Parathormone assay

When indicated, individualize testing for

Vitamin A, copper, zinc, selenium and thiamine assays

Homocysteine and methylmalonic acid assays

24 hour urine excretion for calcium

Imaging

Bone densitometry at 2 years and as indicated thereafter

TABLE 2: Post-bariatric Surgery Evaluation [2-3, 25, 37]

The management of bariatric surgery patients includes preoperative assessment of nutrient status, patient education, and post-surgery follow-up to reinforce the principles associated with long-term weight loss and its maintenance, adopting a multidisciplinary approach. Follow-up is the responsibility of several disciplines, including the bariatric surgeon, physician, nutritionist, psychiatrist, gastroenterologist, and others [3, 33, 36-37].

Overwhelmed with her complications, our patient stated during the short encounter, "Doc, though I have lost weight and fit in my favorite gown, I feel I was healthier when I was fat 
before the surgery than I do now!" After all, she was living with a hemoglobin below 4, which could have been prevented by proper follow-up post-surgery!

\section{Conclusions}

Current guidelines emphasize the evaluation and management of overweight and obese individuals utilizing several approaches. When lifestyle measures and medications are ineffective, bariatric surgery becomes a consideration. Although bariatric surgery results in several desired results, adverse outcomes can also occur. Postoperative management must involve both physician and surgeon. The overall approach begins by optimizing patient status prior to bariatric surgery, followed by appropriate short- and long-term follow-up. Nutrient deficiencies can occur post-bariatric surgery, some with life-threatening complications. Deficiencies can be detected and addressed in a timely manner. Psychological issues are common in these patients before and post-surgery. While the euphoria of weight loss in bariatric patients may be blunted from development of complications and alteration in quality of life, many of these are largely preventable.

\section{Additional Information}

\section{Disclosures}

Human subjects: Consent was obtained by all participants in this study. Conflicts of interest: In compliance with the ICMJE uniform disclosure form, all authors declare the following: Payment/services info: All authors have declared that no financial support was received from any organization for the submitted work. Financial relationships: All authors have declared that they have no financial relationships at present or within the previous three years with any organizations that might have an interest in the submitted work. Other relationships: All authors have declared that there are no other relationships or activities that could appear to have influenced the submitted work.

\section{References}

1. Jensen MD, Ryan DH, Apovian CM, et al.: 2013 AHA/ACC/TOS guideline for the Management of Overweight and Obesity in Adults: A Report of the American College of Cardiology/American Heart Association Task Force on Practice Guidelines and The Obesity Society. Circulation. 2014. 129:102-38. 10.1161/01.cir.0000437739.71477

2. Torres AJ, Rubio MA: The Endocrine Society's Clinical Practice Guideline on endocrine and nutritional management of the post-bariatric surgery patient: Commentary from a European Perspective. Eur J Endocrinol. 2011, 165:171-6. 10.1530/EJE-11-0357

3. Allied Health Sciences Section Ad Hoc Nutrition Committee, Aills L, Blankenship J, Buffington C, Furtado M, Parrott J: ASMBS allied health nutritional guidelines for the surgical weight loss patient: Surgery for obesity and related diseases. Surg Obes Relat Dis. 2008, 4:S73-108. 10.1016/j.soard.2008.03.002

4. Clinical Issues Committee of the American Society for Metabolic and Bariatric Surgery: American Society for Metabolic and Bariatric Surgery position statement on emergency care of patients with complications related to bariatric surgery. Surg Obes Relat Dis. 2010, 4:115-7. 10.1016/j.soard.2009.11.012

5. Jensen MD, Ryan DH: New obesity guidelines: Promise and potential. . JAMA. 2014, 311:23-4. 10.1001/jama.2013.282546

6. Yanovski SZ, Yanovski JA: Long term drug treatment for obesity. A systematic and clinical review. JAMA. 2014, 311:74-86. 10.1001/jama.2013.281361

7. Jastrzębska-Mierzyńska M, Ostrowska L, Hady HR, Dadan J: Assessment of dietary habits, nutritional status and blood biochemical parameters in patients prepared for bariatric surgery: A preliminary study. Wideochir Inne Tech Malo Inwazyjne. 2012, 7:156-65. 10.5114/wiitm.2011.27581

8. Sawaya RA, Jaffe J, Friedenberg L, Friedenberg FK: Vitamin, mineral and drug absorption 
following bariatric surgery. Curr Drug Metab. 2012, 13:1345-55.

9. Ikramuddin S, Livingston EH: New insights on bariatric surgery outcomes. JAMA. 2013, 11:2401-2. 10.1001/jama.2013.280927

10. Adams TD, Davidson LE, Litwin SE, et al.: Health benefits of gastric bypass surgery after 6 years. JAMA. 2012, 308:1122-31.

11. Ikramuddin S, Korner J, Lee WJ, et al.: Roux-en-Y gastric bypass versus intensive medical management for the control of type 2 diabetes, hypertension, and hyperlipidemia: the Diabetes Surgery Study randomized controlled trial. JAMA. 2013, 309:2240-9. 10.1001/jama.2013.5835

12. Courcoulas AP, Christian NJ, Belle HS, et al.: Weight change and health outcomes at 3 years after bariatric surgery among individuals with severe obesity. JAMA. 2013, 310:2416-25. 10.1001/jama.2013.280928

13. Adams TD, Gress RE, Smith SC et al.: Long-term mortality after gastric bypass surgery. NEJM. 2007, 357:753-61.

14. Love AL, Billett HH: Obesity, bariatric surgery, and iron deficiency: true, true, true and related. Am J Hematol. 2008, 83:403-9.

15. Bal BS, Finelli FC, Shope TR, Koch TR: Nutritional deficiencies after bariatric surgery. Nat Rev Endocrinol. 2012, 8:544-56. 10.1038/nrendo.2012.48

16. Pech N, Meyer F, Lippert H, et al.: Complications and nutrient deficiencies two years after sleeve gastrectomy. BMC Surg. 2012, 12:13. 10.1186/1471-2482-12-13

17. Shankar P, Boylan M, Sriram K: Micronutrient deficiencies after bariatric surgery. Nutrition. 2010, 26:1031-7. 10.1016/j.nut.2009.12.003

18. Moyer VA: U.S. Preventive Services Task Force: Behavioral counseling interventions to promote a healthful diet and physical activity for cardiovascular disease prevention in adults: U.S. Preventive Services Task Force Recommendation Statement. Ann Intern Med. 2012, 157:367-71.

19. Dharmarajan TS, Kanagala MR, Murakonda P, et al.: Do acid lowering agents affect vitamin B12 status in older adults?. J Am Med Dir Assoc. 2008, 9:162-7. 10.1016/j.jamda.2007.10.004

20. Dharmarajan TS, Norkus EP: Does long-term PPI use result in vitamin B12 deficiency in elderly individuals?. Nat Clin Pract Gastroenterol Hepatol. 2008, 5:604-5.

10.1038/ncpgasthep1263

21. Dharmarajan TS, Gunturu SG, Pitchumoni CS: Iron, copper and zinc. In Geriatric Gastroenterology. Pitchumoni CS, Dharmarajan TS (ed): Springer, New York; 2012. 177-83.

22. Muñoz M, Botella-Romero F, Gómez-Ramírez S, et al: Iron deficiency and anemia in bariatric surgical patients: Causes, diagnosis and proper management. Nutr Hosp. 2009:640-54.

23. Lam JR, Schneider JL, Zhao W, Corley DA: Proton pump inhibitor and histamine 2 receptor antagonist use and vitamin B12 deficiency. JAMA. 2013, 310:2435-42.

10.1001/jama.2013.280490

24. Goddard AF, James MW, McIntyre AS, Scott BB; British Society of Gastroenterology: Guidelines for the management of iron deficiency anaemia. Gut. 2011, 60:1309-16. 10.1136/gut.2010.228874

25. Mechanick JI, Youdim A, Jones DB, et al.: Clinical practice guidelines for the perioperative nutritional, metabolic, and nonsurgical support of the bariatric surgery patient--2013 update: Cosponsored by American Association of Clinical Endocrinologists, the Obesity Society, and American Society for Metabolic \& Bariatric Surgery. Surg Obes Relat Dis. 2013, 9:159-91. 10.1016/j.soard.2012.12.010

26. Aarts EO, van Wageningen B, Janssen IM, Berends FJ: Prevalence of Anemia and Related Deficiencies in the First Year following Laparoscopic Gastric Bypass for Morbid Obesity. J Obes. 2012, 2012:193705. 10.1155/2012/193705

27. American Geriatrics Society 2012 Beers Criteria Update Expert Panel: American Geriatrics Society updated Beers Criteria for potentially inappropriate medication use in older adults. J Am Geriatr Soc. 2012:616-631. 10.1111/j.1532-5415.2012.03923.x

28. Carmel R: Cobalamin, the stomach, and aging. Am J Clin Nutr. 1997, 66:750-759.

29. Dharmarajan TS, Adiga GU, Norkus EP: Vitamin B12 deficiency. Recognizing subtle symptoms in older adults. Geriatrics. 2003, 58:30-4.

30. Dharmarajan TS, Gunturu SG: B12 and folic acid. In Geriatric Gastroentrology. Pitchumoni CS,Dharmarajan TS (ed): Springer, New York; 2012. 161-176.

31. Allen LH: Causes of vitamin B12 and folate deficiency. Food Nutr Bull. 2008, 29:20-34. 


\section{Cureus}

32. Dewey M, Heuberger R: Vitamin D and calcium status and appropriate recommendations in bariatric surgery patients. Gastroenterol Nurs. 2011, 34:367-74.

10.1097/SGA.0b013e318229bcd0

33. Gudzune KA, Huizinga MM, Chang HY, et al.: Screening and diagnosis of micronutrient deficiencies before and after bariatric surgery. Obes Surg. 2013, 23:10-1007.

34. Luppino FS, de Wit LM, Bouvy PF, et al.: Overweight, obesity, and depression: A systematic review and meta-analysis of longitudinal studies. Arch Gen Psychiatry. 2010, 67:220-229.

10.1001/archgenpsychiatry.2010.2

35. Peterhänsel C, Petroff D, Klinitzke G, et al.: Risk of completed suicide after bariatric surgery: A systematic review. Obes Rev. 2013, 14:369-82. 10.1111/obr.12014

36. Pull CB: Current psychological assessment practices in obesity surgery programs: what to assess and why. Curr Opin Psychiatry. 2010, 23:30-6. 10.1097/YCO.0b013e328334c817

37. Fujioka K: Follow-up of nutritional and metabolic problems after bariatric surgery. Diabetes Care. 2005, 28:481-4. 